\title{
Closed-loop insulin delivery for treatment of type 1 diabetes
}

Daniela Elleri, David B Dunger and Roman Hovorka*

\begin{abstract}
Type 1 diabetes is one of the most common endocrine problems in childhood and adolescence, and remains a serious chronic disorder with increased morbidity and mortality, and reduced quality of life. Technological innovations positively affect the management of type 1 diabetes. Closed-loop insulin delivery (artificial pancreas) is a recent medical innovation, aiming to reduce the risk of hypoglycemia while achieving tight control of glucose. Characterized by real-time glucose-responsive insulin administration, closed-loop systems combine glucose-sensing and insulin-delivery components. In the most viable and researched configuration, a disposable sensor measures interstitial glucose levels, which are fed into a control algorithm controlling delivery of a rapidacting insulin analog into the subcutaneous tissue by an insulin pump. Research progress builds on an increasing use of insulin pumps and availability of glucose monitors. We review the current status of insulin delivery, focusing on clinical evaluations of closed-loop systems. Future goals are outlined, and benefits and limitations of closed-loop therapy contrasted. The clinical utility of these systems is constrained by inaccuracies in glucose sensing, interand intra-patient variability, and delays due to absorption of insulin from the subcutaneous tissue, all of which are being gradually addressed.
\end{abstract}

\section{Challenges for type 1 diabetes management}

Type 1 diabetes is a chronic disease caused by T-cellmediated autoimmune destruction of the pancreatic $\beta$ cells in genetically predisposed individuals [1]. Insulin discovery in the early 1920 s transformed diabetes from a uniformly fatal condition into a disease requiring lifelong insulin-replacement therapy. The Diabetes Control

\footnotetext{
* Correspondence: rh347@cam.ac.uk

Department of Paediatrics and Institute of Metabolic Science, University of Cambridge, Hills Road, Cambridge, CB2 0QQ, UK
}

and Complication Trial linked tight control of glucose to prevention of long-term diabetes-related vascular complications [2]. Intensification of insulin therapy has become an essential treatment method, but it has been hindered by an increased risk of hypoglycemia [3]. Severe hypoglycemia may lead to seizures or loss of consciousness, and can be life-threatening. Fear of hypoglycemia by patients and caregivers may adversely affect patients' quality of life and psychological well-being [4], and may result in 'over-compensatory' behaviors such as overeating or taking less insulin [5].

Technological innovations continue to benefit the management of type 1 diabetes. Novel rapid and longacting insulin analogs and more physiological insulindelivery systems including smart insulin pumps are increasingly being used. Glucose monitoring is evolving, leading to greater availability of subcutaneous continuous monitors, which provide frequent, real-time, and minimally invasive glucose measurements [6]. Sensoraugmented pump therapy increases convenience by integrating continuous glucose monitoring with an insulin pump. Despite these advances, the current best management of glucose control is still inadequate. Sensor-augmented pump therapy is unable to prevent severe hypoglycemia, with an incidence in patients using such therapy similar to that observed in those using conventional therapy [7]. Glucose levels in adults are above the target glucose level of $10 \mathrm{mmol} / \mathrm{l}$ for more than 8 hours per day, with even higher rates observed in the pediatric and adolescent populations [8]. Automated systems modulating insulin delivery according to sensor glucose levels, independently of patient supervision, may be needed to fully exploit existing glucose-sensing and insulin-delivery technologies, and in particular to protect against nocturnal hypoglycemia and minimize the impact of noncompliant behaviors.

In this review, we examine the current status of closed-loop insulin-delivery systems, extending previous work [9-12], while focusing on their clinical applications 
and evaluations. Future goals are outlined, and the benefits and limitations of closed-loop therapy contrasted.

\section{Closed-loop insulin delivery The artificial pancreas}

Closed-loop insulin delivery, also referred to as the artificial pancreas, is an emerging therapeutic approach for people with type 1 diabetes. It is a medical device consisting of a linked continuous glucose monitor and an insulin pump. Wireless communication facilitates automated data transfer between components without the need for human intervention. A schematic view of the artificial pancreas and the physiological feedback normally provided by the $\beta$-cell is shown in Figure 1 .

The novelty of this approach resides in the real-time feedback between glucose levels and insulin delivery, similar to that presented by the $\beta$-cell. Insulin delivery is modulated at intervals of 1 to 15 minutes, depending on interstitial glucose levels, in contrast to the pre-programmed insulin delivery that takes place during conventional insulin pump treatment.

The key component of the artificial pancreas is the control algorithm, which directs insulin delivery according to glucose levels while accounting for inherent measurement errors and kinetic delays. Various algorithms have been developed [13], but two main categories are the most relevant: the proportional-integral-derivative control (PID) $[14,15]$ and the model-predictive control (MPC) [16-18].

PID algorithms adjust insulin delivery by considering deviations from a target glucose level (proportional component), the area under the curve between the measured and the target glucose level (integral component), and the rate of change in the measured glucose levels (derivative component) [15].

MPC algorithms, by contrast, employ a mathematical model of human glucose regulation to link insulin delivery and glucose excursions as described in numerous theoretical, animal, and computer-simulation studies [16,18-22]. Insulin delivery is calculated by minimizing the difference between forecasted glucose concentrations and the target glucose levels over a prediction window of 1.5 to 3 hours, or longer.

MPC algorithms can be regarded as proactive; they forecast glucose levels in anticipation of the glucoselowering effect of administered insulin and of announced disturbances such as meals and physical activity. PID algorithms, by contrast, can be considered reactive, as they respond to observed glucose levels and are less equipped to handle announced meals and patient-directed insulin boluses. The safety of control algorithms can be enhanced by a supervisory module, which constrains insulin delivery by limiting the maximum insulin rate or by suspending insulin delivery when glucose levels are low or decreasing rapidly $[23,24]$.

The MPC method is well suited to compensate for time delays associated with the subcutaneous route of insulin administration and interstitial glucose measurements. Other algorithms have been tested clinically, such as fuzzy logic, which is developed from qualitative approximations of clinical judgment by diabetes
A

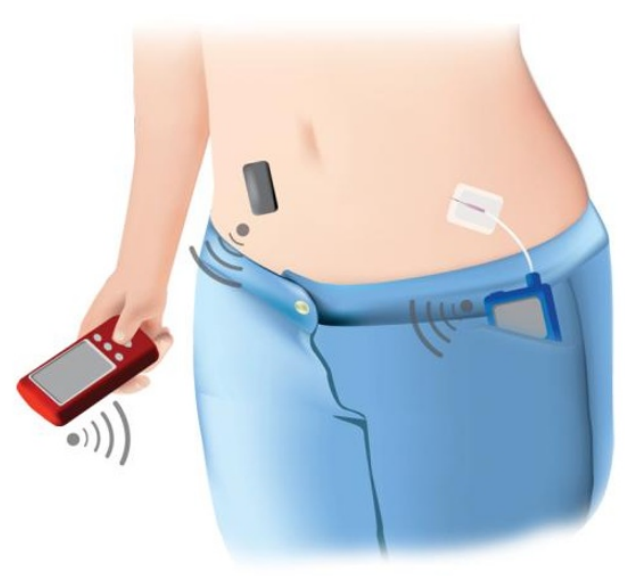

B

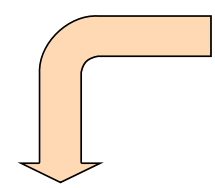

Glucose
level

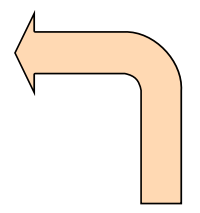

Sensing

(glucose sensor)

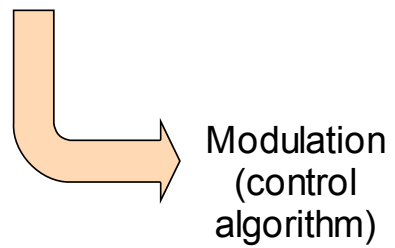

Delivery (insulin pump)

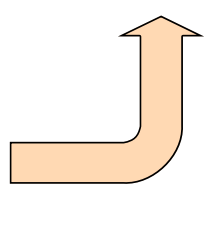

Figure 1 An illustrative representation of a closed-loop insulin delivery system. (A) A sensor (black rectangle) transmits information about interstitial glucose levels to a handheld device about the size of a cellphone (red box) which holds a control algorithm and interacts with the user. An insulin pump (blue box in the pocket) delivers a rapid-acting insulin analog subcutaneously. Insulin delivery is modulated by the control algorithm. The communication between the system components is wireless. The control algorithm can also reside within the insulin pump. (Adapted from Hovorka [12]). (B) The closed loop replicates the physiological feedback normally provided by the $\beta$-cell. 
practitioners [25], a combination of MPC and PID algorithms for insulin and glucagon delivery [19], or a PID with insulin feedback [26]. One of the objectives of the current research is to integrate existing control algorithms within increasingly sophisticated insulin pumps and continuous glucose monitors.

\section{Progress thus far}

It is anticipated that the artificial pancreas will evolve with increasing technology sophistication and more comprehensive treatment objectives [27] (Table 1). Early generations of the artificial pancreas are likely to provide benefits in terms of reduced incidence of hypoglycemia. Benefits may be population-specific; for example, compliant, motivated subjects may benefit from a reduced risk of hypoglycemia whereas less compliant subjects, including adolescents, may benefit from reduced glucose levels. Follow-up closed-loop applications may address hyperglycemia, postprandial control and other lifestyle changes, including exercise. Meals and exercise can be 'announced' to the control algorithm, and prandial insulin boluses can be delivered in the conventional way simplifying closedloop operation. In a more challenging 'fully closed-loop' configuration, the control algorithm is not aware of meals and exercise, and delivers insulin solely based on sensor glucose levels. Glucagon coadministration can be used to counteract peripheral overinsulization following insulin boluses or delayed insulin absorption.

Apart from the low glucose suspend (LGS) approach described below, which has entered postmarketing stage, all other approaches are under investigation in controlled laboratory conditions with realistic plans to perform studies under free-living conditions. Table 2 outlines the status and achievements of various closedloop approaches.

\section{Approaches to reduce incidence of hypoglycemia Low glucose suspend}

Hypoglycemia associated with low sensor-measured glucose levels sustained for 2 to 4 hours may lead to seizures [28]. The body's defensive mechanisms against hypoglycemia are impaired during the night in people with type 1 diabetes, who have lost the ability to release the appropriate counter-regulatory hormones [29-32]. The simplest approach to reduce severity of hypoglycemia is to interrupt insulin delivery. The LGS function was the first example of a commercial application of closed-loop insulin delivery. An insulin pump with an integrated continuous glucose monitoring (CGM) (Para$\operatorname{digm}^{\circledR}$ Veo; Medtronic Diabetes, Northridge, CA, USA) automatically suspends insulin delivery for up to 2 hours when hypoglycemia is detected and the hypoglycemia alarm is not acknowledged by the patient [33]. Patients may be unconscious during hypoglycemia, and their ability to respond to alarms is reduced. Thus, a considerable safety benefit may be obtained from the LGS function. However, concerns have been raised about the attendant hyperglycemia that can result, especially from false-positive hypoglycemia detection. The hyperglycemia risk is not negligible, but thus far only mild rebound hyperglycemia and minimal ketonaemia have been reported after a temporary suspension of insulin administration [34-38].

The LGS function aims to reduce the severity of hypoglycemia, but does not prevent it, which was the objective of work by Buckingham et al., who developed and demonstrated, in laboratory settings, the effectiveness of an algorithm to discontinue insulin delivery when pending hypoglycemia was predicted [39]. This approach was investigated in adults in a clinical setting. Using a pump shut-off time of 90 minutes and a glucose threshold of $4.4 \mathrm{mmol} / \mathrm{l}, 56 \%$ of hypoglycemic episodes were prevented at a prediction horizon of 30 minutes, and $80 \%$ when the horizon was extended to 45 minutes. This approach was then tested overnight in young people, in whom hypoglycemia was induced by gradually increasing the subcutaneous insulin delivery [40]. Hypoglycemia was prevented in up to $84 \%$ of cases, using five prediction algorithms. All these prediction algorithms used a 35-minute prediction horizon to allow time for

Table 1 Closed-loop approaches according to treatment objective

\begin{tabular}{|c|c|}
\hline Objective & Insulin-delivery modulation \\
\hline $\begin{array}{l}\text { Reduce severity and/or duration of } \\
\text { hypoglycemia }\end{array}$ & Suspension of insulin delivery at hypoglycemia (low glucose suspend) \\
\hline Hypoglycemia prevention & Pre-emptive suspension/reduction of insulin delivery before hypoglycemia occurs \\
\hline Control to range & $\begin{array}{l}\text { Modulation (increase or decrease) of insulin delivery outside target range to limit hypoglycemia and } \\
\text { hyperglycemic excursions }\end{array}$ \\
\hline Overnight glucose control & Modulation of insulin delivery for nocturnal glucose control; lifestyle disturbances have limited effect \\
\hline $\begin{array}{l}\text { Closed-loop system with meal/exercise } \\
\text { announcement }\end{array}$ & $\begin{array}{l}\text { Modulation of insulin delivery after meals using boluses administered by patient with announcement of } \\
\text { these, and exercise to the algorithm }\end{array}$ \\
\hline Fully closed-loop system & $\begin{array}{l}\text { Modulation of insulin delivery when the control algorithm is unaware of meals, exercise, stress and other } \\
\text { lifestyle disturbances that affect glucose control; glucagon may be coadministered to reduce risk of } \\
\text { hypoglycemia }\end{array}$ \\
\hline
\end{tabular}


Table 2 Summary of achieved results

\begin{tabular}{|c|c|c|c|}
\hline Objective/approach & Status & Results & Ref. \\
\hline Low glucose suspend & Postmarketing studies & $\begin{array}{l}\text { Reduced nocturnal hypoglycemia in those with greatest risk; well- accepted } \\
\text { by patients }\end{array}$ & {$[61,62]$} \\
\hline $\begin{array}{l}\text { Suspend to prevent low } \\
\text { glucose }\end{array}$ & $\begin{array}{l}\text { Laboratory studies; } \\
\text { home studies planned }\end{array}$ & $\begin{array}{l}\text { Prevention of } 80 \% \text { of events of nocturnal hypoglycemia; effective as part of } \\
\text { overnight closed-loop system }\end{array}$ & {$[39,40]$} \\
\hline Treat to range & $\begin{array}{l}\text { Laboratory testing } \\
\text { underway }\end{array}$ & - & - \\
\hline Overnight & $\begin{array}{l}\text { Laboratory studies; } \\
\text { home studies planned }\end{array}$ & $\begin{array}{l}\text { Increased time spent in target glucose range by } 20 \% \text { in adolescents and } \\
\text { adults; reduced risk of nocturnal hypoglycemia }\end{array}$ & {$[24,43]$} \\
\hline Meal announcement & Laboratory studies & $\begin{array}{l}\text { Feasibility documented in children, adults, and pregnant women using } \\
\text { various control algorithms; preferred option by most investigators }\end{array}$ & {$[26,44,46,58,63]$} \\
\hline Fully closed-loop & Laboratory studies & $\begin{array}{l}\text { Feasibility documented in children and adults; addition of small prandial } \\
\text { bolus improves control; delayed insulin absorption/action remains a challenge }\end{array}$ & {$[25,45,64]$} \\
\hline $\begin{array}{l}\text { Fully closed-loop with } \\
\text { glucagon coadministration }\end{array}$ & Laboratory studies & $\begin{array}{l}\text { Feasibility documented in adults; glucagon helpful but cannot always } \\
\text { overcome insulin overdelivery }\end{array}$ & {$[47,48]$} \\
\hline
\end{tabular}

the pump suspension to be effective in lowering insulin levels once basal infusion was suspended.

\section{Overnight closed-loop}

Most severe hypoglycemic episodes occur during sleep between midnight and 8 am [41]. As overnight glucose control is not complicated by meals or physical activity, closed-loop could help prevent nocturnal hypoglycemia. This is a common clinical problem of great concern to parents and carers of children with type 1 diabetes [42].

Over the past 4 years, diabetes research at Cambridge University has focused on the development and testing of overnight closed-loop insulin delivery systems. Clinical studies have been performed in children, adults and pregnant women $[24,43,44]$, evaluating various scenarios to reproduce real-life challenges for overnight glucose control, which could potentially predispose to nocturnal hypoglycemia, such as afternoon exercise or the consumption of alcohol. Evening meals of different sizes and compositions were also tested. An MPC algorithm was used to determine basal insulin delivery according to sensor glucose readings, whereas prandial insulin boluses were administered based on the subjects' standard practice. Most of those clinical studies adopted a randomized crossover design comparing closed-loop insulin delivery with the conventional insulin pump therapy.

In these randomized crossover studies, the overnight closed-loop system significantly increased the percentage of time that plasma glucose levels were within a target range of 3.9 to $8.0 \mathrm{mmol} / \mathrm{l}$ in children and adolescents (from $40 \%$ to $60 \%, P=0.002$ ) and in adults (from $50 \%$ to $76 \%, P<0.001$ ). The effectiveness of the closed-loop system was most pronounced after midnight, when the system became fully effective. Combined results of both young and adult patients after midnight during closedloop and the conventional pump therapy are summarized in Figure 2. Notably, these results indicate that the closed-loop system resulted in a significantly reduced time spent with glucose below the target range of 3.9 $\mathrm{mmol} / \mathrm{l}$ both in young (from $4.1 \%$ to $2.1 \%, P=0.03$ ) and adult (from $6.7 \%$ to $2.8 \%, P=0.04$ ) patients.

\section{Fully closed-loop versus closed-loop with meal}

\section{announcement}

Two main closed-loop approaches have been adopted in the clinical studies for prandial insulin delivery: 'fully closed-loop' and 'closed-loop with meal announcement' [9]. A fully closed-loop system delivers insulin without information about the size or time of meals, whereas information about meals together with information about manually administered prandial insulin boluses is provided to closed-loop systems adopting the "meal announcement' approach. In a hybrid system, the delivery of pre-meal insulin boluses remains one of the tasks for which patients are responsible, with the closed-loop system automatically determining the insulin delivery between meals [27].

The hybrid system with meal-time priming boluses has been shown to reduce postprandial hyperglycemia compared to a fully closed-loop system [45]. As delays in insulin absorption of the order of 30 to 100 minutes are a major challenge for safe and effective postprandial glucose control, this hybrid approach may be considered a transition step from 'closed-loop with meal announcement'.

The feasibility and efficacy of MPC-based closed-loop insulin delivery was also recently demonstrated in women with type 1 diabetes throughout different stages of pregnancy [44]. Near-optimal nocturnal glycemic control was obtained with the closed-loop system both in early and late pregnancy, coping well with both the longitudinal changes in insulin requirements and the insulin sensitivity associated with pregnancy. Studies of a well-controlled cohort of pregnant women suggested a reduced risk of very low glucose levels with closed-loop insulin delivery, but otherwise similar glucose control [46].

Glucagon coadministration has also been investigated with the fully closed-loop approach $[47,48]$. Although 


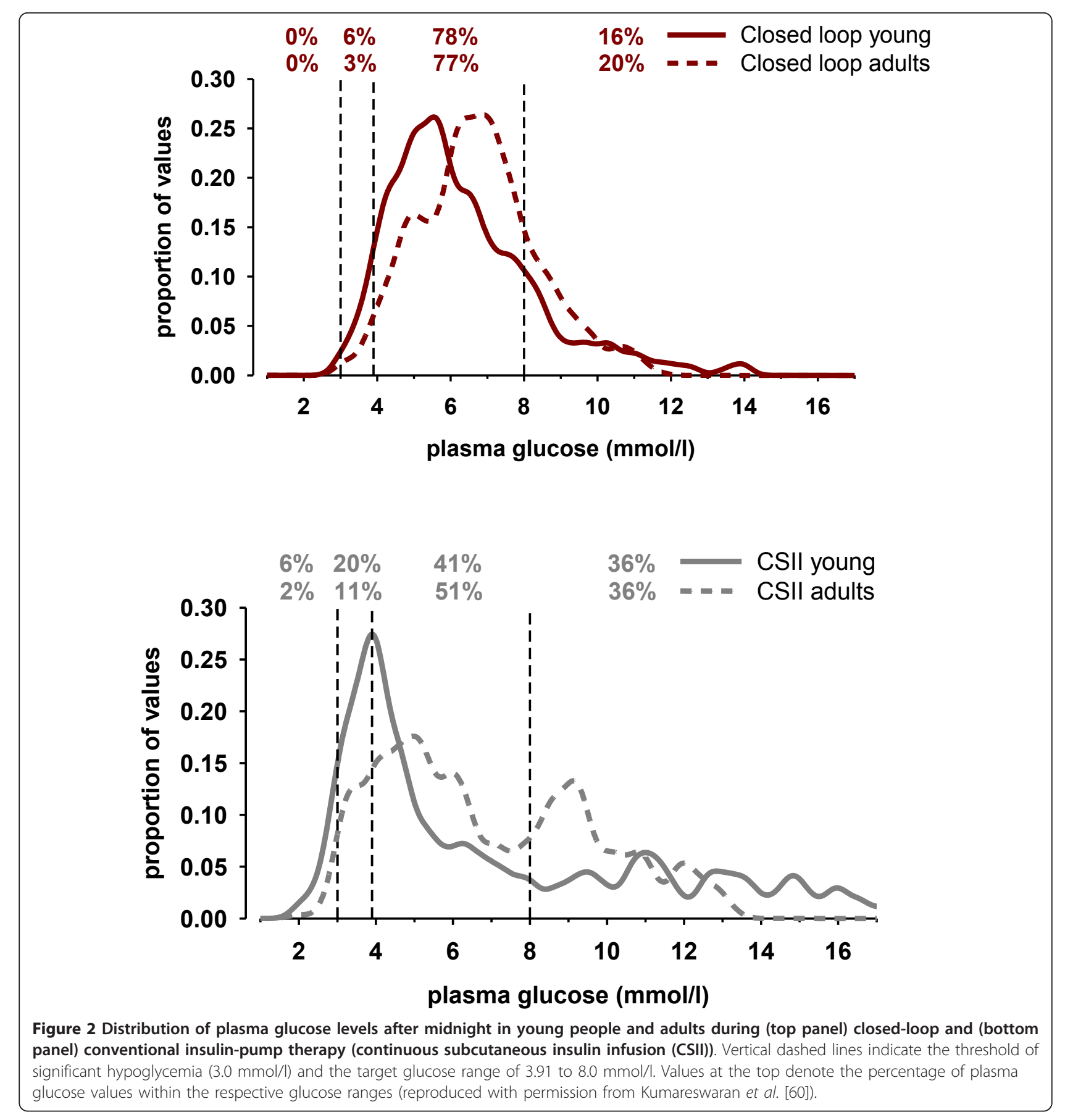

effective in reducing the risk of hypoglycemia, glucagon cannot be fully relied upon to reverse the effect of insulin overdelivery.

\section{Towards home studies}

\section{In silico testing}

Evaluation of closed-loop systems in a controlled laboratory setting is an essential step to assess safety and efficacy before moving to home settings, where everyday life poses additional challenges for effective closed-loop performance. In silico studies play a crucial role in complementing clinical testing, and address scenarios that cannot, for practical or ethical reasons, be tested in clinical studies [49-51].

A computer-based simulation environment developed at Cambridge University builds on a model of glucose regulation, glucose sensing and insulin-pump delivery. It includes a virtual population of subjects with type 1 
diabetes with a range of insulin-sensitivity and glucoregulatory parameters, to represent both inter-subject and intra-subject variability [49] Pre-clinical in silico testing enables us to assess scenarios that are expected to occur rarely but could be potentially harmful. For example, simulations can evaluate the system's response to sensor-data dropouts, large calibration errors, communication failures, unannounced meals, or errors in carbohydrate estimation and thus bolus dosing [51]. Different CGM devices or different algorithms can be tested. Another simulator has been accepted by the US Food and Drug Administration to replace animal testing, and has been widely used for this purpose [50]. The simulator developed by the Medtronic team [52] has complemented animal testing, and has been instrumental in tuning the Medtronic PID algorithm [26,45].

\section{Transitional and early home studies}

Transition to the outpatient studies could be performed gradually with an intermediate phase under supervision of the research team in the subject's home, or at a transitional clinical or hotel-like research facility. The transition phase needs to emphasize education to operate the closed-loop system correctly and confidently. Competency-assessment tools may be used to ensure subjects' knowledge and ability. User acceptance and user friendliness are important aspects that may affect study results, quality of life, and ultimately technology adoption. Subjects' satisfaction may be assessed by the use of questionnaires or qualitative interviews [53].

Home testing of overnight closed-loop is feasible with present technologies. Pilot studies may evaluate efficacy, safety and utility over a short period of time, whereas longer studies are needed to demonstrate effectiveness on glycemic control and rates of hypoglycemia. Specific challenges of day-time glucose control, such as meal intake and exercise, will need to be considered when moving to a full-time (24 hours a day, 7 days a week) closed-loop system.

\section{Expectations for clinical practice}

The main goal of closed-loop therapy is to achieve good glycemic control while reducing the risk of hypoglycemia in people with type 1 diabetes. Although reduction in HbA1c levels is a common key outcome expected by the regulatory authorities, it is important to consider that for some patients, avoidance of severe recurrent hypoglycemia may be the more important focus. Improvement in glycemic variability could be an important target for those subjects with acceptable HbA1c and low incidence of severe hypoglycemia. Results thus far indicate that these targets may be achieved with closed-loop therapy.

Despite the perceived benefits of closed-loop therapy, it is essential to set realistic goals to keep up with reasonable clinical expectations. Furthermore, the impact of this novel treatment tool on quality of life will need to be assessed. Current closed-loop systems are limited by suboptimal performance of the available system components, which include CGM devices, insulin formulations, and insulin-delivery systems. For example, the accuracy of commercially available CGM devices is impaired by errors arising from incorrect calibration, rapid glucose changes, and glucose levels within the hypoglycemic range. Sensor failures may lead to termination of closed-loop operation. Similarly, reduced accuracy of insulin delivery at low volumes by current insulin pumps could negatively affect the performance of closed-loop systems in patients with low insulin requirements. The reliability of wireless communication between the components also needs to be addressed.

Patient engagement in the daily use of closed-loop systems is also of importance. It is possible that the introduction of the artificial pancreas as an integral part of diabetes management will change current clinical practice. Although patients could be released from the constant attention to insulin adjustments they presently experience, their active engagement will still be needed during prolonged exercise, illness, puberty or pregnancy, which are associated with significant changes in insulin sensitivity and requirements. For this reason, specific training and education in the use of closed-loop therapy will be needed by both patients and healthcare professionals. The benefits and limitations of the system will also need to be clarified.

\section{The future: perfecting closed-loop therapy}

For closed-loop insulin delivery to be used widely, improvements may need to increase effectiveness, safety, and convenience gradually (Table 3). Specific challenges include postprandial glucose control. Improved understanding of postprandial glucose fluctuations will provide additional information to refine control algorithms. Research using stable glucose isotopes to measure gut absorption of meals of different sizes or compositions is underway [54]. A dual-hormone closed-loop approach is also under investigation using, for example, pramlintide, an amylin analog that is normally released by $\beta$-cells along with insulin after a meal. Amylin delays glucose absorption, thus improving post-meal glucose control [55]. Similarly, a more physiologic approach will be needed to cope with exercise-related changes in insulin sensitivity.

A major turning point in the development of closedloop systems will be the introduction of insulin formulations with faster absorption. With rapid-acting insulin analogs, the maximum blood-glucose-lowering effect occurs after up to 90 to $120 \mathrm{~min}$. This lag 
Table 3 Goals to improve gradually closed-loop performance

\begin{tabular}{ll}
\hline Factor & Desirable improvements \\
\hline Insulin delivery & Faster absorption \\
Glucose sensing & Increased accuracy and reliability; reduced false-positive hypoglycemia alarms \\
Insulin modulation & Adaptive algorithms \\
Dual-hormone systems & Dual-chamber pumps \\
Communication between glucose sensor and insulin & More reliable connectivity; standardized communication protocol \\
pump & \\
Human factors & Reduced size of devices; enhanced ease of use; sensing and delivery from a single body \\
& port \\
\hline
\end{tabular}

constitutes one of the greatest challenges for closedloop systems, and availability of faster insulin analogs or devices accelerating insulin absorption will eventually translate into more effective and safer insulin delivery. These pharmaceutical developments are ongoing [56,57].

Engineering factors needing further attention include accurate insulin delivery at low rates, more reliable CGM devices, dependable wireless communication, and improved control algorithms. Human factors should consider usability, safety and training/education components. The availability of smaller and more user-friendly devices might be particularly important for children [42]. Telemonitoring is also seen as an additional feature to enhance safety, although its practicability and utility are yet to be established. The clinical team can be informed about system malfunctions, subject compliance, and the level of glucose control, with the possibility of remote algorithm updates.

An alternative to subcutaneous insulin delivery is intraperitoneal insulin infusion, which restores the portal/peripheral insulin concentration gradient. Renard et al. evaluated the feasibility and efficacy of a closedloop system with an implantable insulin pump coupled to a subcutaneous glucose sensor [58]. Further progress could be made with an intraperitoneal port to bypass the limitations of implantable insulin pumps [59].

\section{Conclusions}

Closed-loop insulin delivery presents a tangible treatment option and may serve as a bridge to a cure for type 1 diabetes until stem-cell therapy or similar longterm biologic interventions become available. Closedloop insulin delivery may revolutionize not only the way diabetes is managed but also patients' perceptions of living with diabetes, by reducing the burden on patients and carers, and their fears of complications related to diabetes, including those associated with low and high glucose levels. The next step is to confirm the encouraging results collected under controlled laboratory settings in real-life conditions at home.

\section{Acknowledgements and funding}

Supported by the Juvenile Diabetes Research Foundation (\#22-2006-1113, \#22-2007-1801, \#22-2009-801), Diabetes UK (BDA07/0003549, BDA07/ 0003551), European Commission Framework Programme 7 (247138), NIDDK (DK085621), and NIHR Cambridge Biomedical Research Centre.

\section{Authors' contributions}

DE researched data and drafted the report. $\mathrm{RH}$ and DBD contributed to the interpretation of the data, and the writing and critical review of the report. All authors read and approved the final manuscript.

\section{Authors' information}

Daniela Elleri, MD, is a clinical research fellow in Paediatrics at the Institute of Metabolic Science and Department of Paediatrics, University of Cambridge, UK, who is actively involved in the clinical research studies evaluating closed-loop insulin-delivery systems in people with type 1 diabetes. David B Dunger, MD, FRCP and FRCPC, is a Professor of Paediatrics at Addenbrooke's Hospital, University of Cambridge, with has a particular interest in the pathophysiology of diabetes during childhood and adolescence, and the genetic and environmental interactions that determine size at birth and childhood growth. His research group are coordinating the follow-up of large pediatric cohorts designed to investigate the genetics and pathophysiology of diabetes and its complications. Roman Hovorka, BSc, MSc, and PhD, is Principal Research Associate at the Institute of Metabolic Science and Department of Paediatrics, University of Cambridge, UK. His current research interests include evaluation of medical technologies to support diagnosis and treatment of diabetes and related metabolic diseases. He leads research team developing and testing closed-loop insulin delivery systems in type 1 diabetes, and he also works on developing approaches for glycemic control in the critically ill.

\section{Competing interests}

$\mathrm{RH}$ has received speaker honoraria from Minimed Medtronic, Lifescan, Eli Lilly, and Novo Nordisk, has served on an advisory panel for Animas and Minimed Medtronic, has received license fees from BBraun and Beckton Dickinson; and has served as a consultant to Beckton Dickinson, BBraun and Profil. DE has no competing financial interests. $\mathrm{RH}$ and DBD have patent applications pending.

Received: 11 August 2011 Accepted: 9 November 2011

Published: 9 November 2011

\section{References}

1. Todd JA: Etiology of type 1 diabetes. Immunity 2010, 32:457-467.

2. Diabetes Control and Complication Trial Study Group (DCCT): The effect of intensive treatment of diabetes on the development and progression of long-term complications in insulin-dependent diabetes-mellitus. N Engl J Med 1993, 329:977-986.

3. Cryer PE: The barrier of hypoglycemia in diabetes. Diabetes 2008, 57:3169-3176

4. Nixon R, Pickup JC: Fear of hypoglycemia in type 1 diabetes managed by continuous subcutaneous insulin infusion: is it associated with poor glycemic control? Diabetes Technol Ther 2011, 13:93-98.

5. Wild D, Von Maltzahn R, Brohan E, Christensen T, Clauson P, GonderFrederick $L$ : A critical review of the literature on fear of hypoglycemia in 
diabetes: Implications for diabetes management and patient education. Patient Educ Couns 2007, 68:10-15.

6. Klonoff DC: Continuous glucose monitoring: roadmap for 21st century diabetes therapy. Diabetes Care 2005, 28:1231-1239.

7. Bergenstal RM, Tamborlane WV, Ahmann A, Buse JB, Dailey G, Davis SN, Joyce C, Peoples T, Perkins BA, Welsh JB, Willi SM, Wood MA: Effectiveness of sensor-augmented insulin-pump therapy in type 1 diabetes. $N$ Engl $J$ Med 2010, 363:311-320.

8. Tamborlane WW, Beck RW, Bode BW, Buckingham B, Chase HP, Clemons R, Fiallo-Scharer R, Fox LA, Gilliam LK, Hirsch IB, Huang ES, Kollman C, Kowalski AJ, Laffel L, Lawrence JM, Lee J, Mauras N, O'Grady M, Ruedy KJ, Tansey M, Tsalikian E, Weinzimer S, Wilson DM, Wolpert H, Wysocki T, Xing D: Continuous glucose monitoring and intensive treatment of type 1 diabetes. N Engl I Med 2008, 359:1464-1476.

9. Hovorka R: Continuous glucose monitoring and closed-loop systems. Diabet Med 2006, 23:1-12

10. Steil GM, Rebrin K: Closed-loop insulin delivery - what lies between where we are and where we are going? Expert Opin Drug Deliv 2005, 2:353-362.

11. Renard $\mathrm{E}$, Costalat $\mathrm{G}$, Chevassus $\mathrm{H}$, Bringer J: Artificial beta-cell: clinical experience toward an implantable closed-loop insulin delivery system. Diabetes Metab 2006, 32:497-502.

12. Hovorka R: Closed-loop insulin delivery: from bench to clinical practice. Nat Rev Endocrinol 2011, 7:385-395.

13. Bequette BW: A critical assessment of algorithms and challenges in the development of a closed-loop artificial pancreas. Diabetes Technol Ther 2005, 7:28-47.

14. Marchetti G, Barolo M, Jovanovic L, Zisser H, Seborg DE: An improved PID switching control strategy for type 1 diabetes. IEEE Trans Biomed Eng 2008, 55:857-865.

15. Steil GM, Panteleon AE, Rebrin K: Closed-loop insulin delivery-the path to physiological glucose control. Adv Drug Deliv Rev 2004, 56:125-144.

16. Hovorka R, Canonico V, Chassin LJ, Haueter U, Massi-Benedetti M, Orsini FM, Pieber TR, Schaller HC, Schaupp L, Vering T, Wilinska ME: Nonlinear model predictive control of glucose concentration in subjects with type 1 diabetes. Physiol Meas 2004, 25:905-920.

17. Magni L, Raimondo DM, Bossi L, Man CD, De NG, Kovatchev B, Cobelli C: Model predictive control of type 1 diabetes: an in silico trial. J Diabetes Sci Technol 2007, 1:804-812.

18. Parker RS, Doyle FJ III, Peppas NA: A model-based algorithm for blood glucose control in type I diabetic patients. IEEE Trans Biomed Eng 1999, 46:148-157.

19. El-Khatib FH, Jiang J, Damiano ER: Adaptive closed-loop control provides blood-glucose regulation using dual subcutaneous insulin and glucagon infusion in diabetic swine. J Diabetes Sci Technol 2007, 1:181-192.

20. Lee H, Buckingham BA, Wilson DM, Bequette BW: A closed-loop artificial pancreas using model predictive control and a sliding meal size estimator. J Diabetes Sci Technol 2009, 3:1082-1090.

21. Wang Y, Dassau E, Doyle FJ III: Closed-loop control of artificial pancreatic Beta -cell in type 1 diabetes mellitus using model predictive iterative learning control. IEEE Trans Biomed Eng 2010, 57:211-219.

22. Grosman B, Dassau E, Zisser HC, Jovanovic L, Doyle FJ III: Zone model predictive control: a strategy to minimize hyper- and hypoglycemic events. J Diabetes Sci Technol 2010, 4:961-975.

23. Kovatchev B, Patek S, Dassau E, Doyle FJ III, Magni L, De NG, Cobelli C: Control to range for diabetes: functionality and modular architecture. $J$ Diabetes Sci Technol 2009, 3:1058-1065.

24. Hovorka R, Allen JM, Elleri D, Chassin LJ, Harris J, Xing D, Kollman C, Hovorka T, Larsen AM, Nodale M, De PA, Wilinska ME, Acerini CL, Dunger DB: Manual closed-loop insulin delivery in children and adolescents with type 1 diabetes: a phase 2 randomised crossover trial. Lancet 2010, 375:743-751.

25. Atlas E, Nimri R, Miller S, Grunberg EA, Phillip M: MD-logic artificial pancreas system: a pilot study in adults with type 1 diabetes. Diabetes Care 2010, 33:1072-1076.

26. Steil GM, Palerm CC, Kurtz N, Voskanyan G, Roy A, Paz S, Kandeel FR: The effect of insulin feedback on closed loop glucose control. J Clin Endocrinol Metab 2011, 96:1402-1408.

27. Kowalski AJ: Can we really close the loop and how soon? Accelerating the availability of an artificial pancreas: a roadmap to better diabetes outcomes. Diabetes Technol Ther 2009, 11:S113-S119.
28. Buckingham B, Wilson DM, Lecher T, Hanas R, Kaiserman K, Cameron F: Duration of nocturnal hypoglycemia before seizures. Diabetes Care 2008, 31:2110-2112.

29. Cryer PE: Glucose counterregulation in normal and diabetic man. Clin Physiol 1985, 5(Suppl 5):61-65.

30. Cryer PE: Mechanisms of hypoglycemia-associated autonomic failure and its component syndromes in diabetes. Diabetes 2005, 54:3592-3601.

31. Simonson DC, Tamborlane W, Defronzo RA, Sherwin RS: Intensive insulin therapy reduces counterregulatory hormone responses to hypoglycemia in patients with type I diabetes. Ann. Intern Med 1985, 103:184-190.

32. Jones TW, Porter P, Sherwin RS, Davis EA, O'Leary P, Frazer F, Byrne G, Stick S, Tamborlane WV: Decreased epinephrine responses to hypoglycemia during sleep. N Engl I Med 1998, 338:1657-1662.

33. Pickup JC: Semi-closed-loop insulin delivery systems: early experience with low-glucose insulin suspend pumps. Diabetes Technol Ther 2011, 13:695-698.

34. Attia N, Jones TW, Holcombe J, Tamborlane WV: Comparison of human regular and lispro insulins after interruption of continuous subcutaneous insulin infusion and in the treatment of acutely decompensated IDDM. Diabetes Care 1998, 21:817-821.

35. Guerci B, Meyer L, Salle A, Charrie A, Dousset B, Ziegler O, Drouin P. Comparison of metabolic deterioration between insulin analog and regular insulin after a 5 -hour interruption of a continuous subcutaneous insulin infusion in type 1 diabetic patients. J Clin Endocrinol Metab 1999, 84:2673-2678.

36. Krzentowski G, Scheen A, Castillo M, Luyckx AS, Lefebvre PJ: A 6-hour nocturnal interruption of a continuous subcutaneous insulin infusion. Metabolic and hormonal consequences and scheme for a prompt return to adequate control. Diabetologia 1983, 24:314-318.

37. Pickup JC, Viberti GC, Bilous RW, Keen H, Alberti KGMM, Home PD, Binder C: Safety of continuous subcutaneous insulin infusion. Metabolic deterioration and glycemic auto-regulation after deliberate cessation of infusion. Diabetologia 1982, 22:175-179.

38. Scheen A, Castillo M, Jandrain B, Krzentowski G, Henrivaux P, Luyckx A, Lefebvre P: A 2-hour nocturnal interruption of continuous subcutaneous insulin infusion induces a delayed and sustained metabolic deterioration in C-peptide negative type-1 (insulin-dependent) diabetic patients. Diabetologia 1983, 25:192-192.

39. Buckingham B, Cobry E, Clinton P, Gage V, Caswell K, Kunselman E, Cameron F, Chase HP: Preventing hypoglycemia using predictive alarm algorithms and insulin pump suspension. Diabetes Technol Ther 2009, 11:93-97.

40. Buckingham B, Chase HP, Dassau E, Cobry E, Clinton P, Gage V, Caswell K, Wikinson J, Cameron F, Lee H, Bequette BW, Doyle FJ III: Prevention of nocturnal hypoglycemia using predictive alarm algorithms and insulin pump suspension. Diabetes Care 2010, 33:1013-1017.

41. Diabetes Control and Complication Trial Study Group (DCCT): Epidemiology of severe hypoglycemia in the diabetes control and complications trial. Am J Med 1991, 90:450-459.

42. Elleri D, Acerini $C L$, Allen JM, Hayes J, Pesterfield C, Wilinska ME, Dunger DB, Hovorka R: Parental attitudes towards overnight closed-loop glucose control in children with type 1 diabetes. Diabetes Technol Ther 2010, 12:35-39.

43. Hovorka R, Kumareswaran $K$, Harris J, Allen JM, Elleri D, Xing D, Kollman C, Nodale M, Murphy HR, Dunger DB, Amiel SA, Heller SR, Wilinska ME, Evans ML: Overnight closed loop insulin delivery (artificial pancreas) in adults with type 1 diabetes: crossover randomised controlled studies. BMJ 2011, 342:d1855.

44. Murphy HR, Elleri D, Allen JM, Harris J, Simmons D, Rayman G, Temple R, Dunger DB, Haidar A, Nodale M, Wilinska ME, Hovorka R: Closed-loop insulin delivery during pregnancy complicated by type 1 diabetes. Diabetes Care 2011, 34:406-411.

45. Weinzimer SA, Steil GM, Swan KL, Dziura J, Kurtz N, Tamborlane WV: Fully automated closed-loop insulin delivery versus semi-automated hybrid control in pediatric patients with type 1 diabetes using an artificial pancreas. Diabetes Care 2008, 31:934-939.

46. Murphy HR, Kumareswaran K, Elleri D, Allen JM, Caldwell K, Biagioni M, Simmons D, Dunger DB, Nodale M, Wilinska ME, Amiel SA, Hovorka R: Safety and efficacy of $24 \mathrm{~h}$ closed-loop insulin delivery in well-controlled pregnant women with type 1 diabetes: a randomized crossover case series. Diabetes Care 2011. 
47. Castle JR, Engle JM, El YJ, Massoud RG, Yuen KC, Kagan R, Ward WK: Novel use of glucagon in a closed-loop system for prevention of hypoglycemia in type 1 diabetes. Diabetes Care 2010, 33:1282-1287.

48. El-Khatib FH, Russell SJ, Nathan DM, Sutherlin RG, Damiano ER: A bihormonal closed-loop artificial pancreas for type 1 diabetes. Sci Transl Med 2010, 2:27ra27.

49. Wilinska ME, Chassin LJ, Acerini CL, Allen JM, Dunger DB, Hovorka R Simulation environment to evaluate closed-loop insulin delivery systems in type 1 diabetes. J Diabetes Sci Technol 2010, 4:132-144.

50. Kovatchev BP, Breton M, Man CD, Cobelli C: In silico preclinical trials: a proof of concept in closed-loop control of type 1 diabetes. J Diabetes Sci Technol 2009, 3:44-55.

51. Wilinska ME, Budiman ES, Taub MB, Elleri D, Allen JM, Acerini $C L$, Dunger DB, Hovorka R: Overnight closed-loop insulin delivery with model predictive control: assessment of hypoglycemia and hyperglycemia risk using simulation studies. J Diabetes Sci Technol 2009, 3:1109-1120.

52. Kanderian SS, Weinzimer S, Voskanyan G, Steil GM: Identification of intraday metabolic profiles during closed-loop glucose control in individuals with type 1 diabetes. J Diabetes Sci Technol 2009, 3:1047-1057.

53. Juvenile Diabetes Research Foundation Continuous Glucose Monitoring Study Group: Satisfaction with continuous glucose monitoring in adults and youths with Type 1 diabetes. Diabet Med 2011, 28(9):1118-1122.

54. Elleri D, Harris J, Kumareswaran K, Allen JM, Haidar A, Nodale M, Swamy A, Wilinska ME, Weston J, Acerini CL, Jackson N, Umpleby AM, Evans ML, Dunger DB, Hovorka R: Glucose appearance of large slowly-absorbed evening meal containing complex carbohydrates $(\mathrm{CHO})$ in type 1 diabetes (T1D). Diabetologia 2010, 53(Suppl 1):S 272

55. Weinzimer SA, Sherr JL, Cengiz E, Kim G, Carria L, Tamborlane WV: Effect of adjuvant injected pramlintide on closed-loop automated insulin delivery. Diabetes 2011, 60(Supll 1):A 253.

56. Hompesch M, Muchmore DB, Morrow L, Vaughn DE: Accelerated insulin pharmacokinetics and improved postprandial glycemic control in patients with type 1 diabetes after coadministration of prandial insulins with hyaluronidase. Diabetes Care 2011, 34:666-668.

57. Steiner S, Hompesch M, Pohl R, Simms P, Flacke F, Mohr T, Pfutzner A, Heinemann L: A novel insulin formulation with a more rapid onset of action. Diabetologia 2008, 51:1602-1606.

58. Renard E, Place J, Cantwell M, Chevassus H, Palerm CC: Closed-loop insulin delivery using a subcutaneous glucose sensor and intraperitoneal insulin delivery: feasibility study testing a new model for the artificial pancreas. Diabetes Care 2010, 33:121-127.

59. Liebl A, Hoogma R, Renard E, Geelhoed-Duijvestijn PH, Klein E, Diglas J, Kessler L, Melki V, Diem P, Brun JM, Schaepelynck-Belicar P, Frei T: A reduction in severe hypoglycaemia in type 1 diabetes in a randomized crossover study of continuous intraperitoneal compared with subcutaneous insulin infusion. Diabetes Obes Metab 2009, 11:1001-1008.

60. Kumareswaran K, Elleri D, Allen JM, Harris J, Xing D, Kollman C, Nodale M, Murphy HR, Amiel SA, Heller SR, Wilinska ME, Acerini CL, Evans ML, Dunger DB, Hovorka R: Meta-analysis of overnight closed-loop randomised studies in children and adults with type 1 diabetes: the Cambridge cohort. J Diabetes Sci Technol 2011.

61. Choudhary P, Shin J, Wang Y, Evans ML, Hammond PJ, Kerr D, Shaw JA, Pickup JC, Amiel SA: Insulin pump therapy with automated insulin suspension in response to hypoglycemia: reduction in nocturnal hypoglycemia in those at greatest risk. Diabetes Care 2011, 34:2023-2025

62. Danne T, Kordonouri O, Holder M, Haberland H, Golembowski S, Remus K, Blasig S, Wadien T, Zierow S, Hartmann R, Thomas A: Prevention of hypoglycemia by using low glucose suspend function in sensoraugmented pump therapy. Diabetes Technol Ther 2011, 13:1-6.

63. Kovatchev B, Cobelli C, Renard E, Anderson S, Breton M, Patek S, Clarke W, Bruttomesso D, Maran A, Costa S, Avogaro A, Dalla MC, Facchinetti A, Magni L, De NG, Place J, Farret A: Multinational study of subcutaneous model-predictive closed-loop control in type 1 diabetes mellitus: summary of the results. J Diabetes Sci Technol 2010, 4:1374-1381.

64. Steil GM, Rebrin K, Darwin C, Hariri F, Saad MF: Feasibility of automating insulin delivery for the treatment of type 1 diabetes. Diabetes 2006, 55:3344-3350.

\section{Pre-publication history}

The pre-publication history for this paper can be accessed here:

http://www.biomedcentral.com/1741-7015/9/120/prepub doi:10.1186/1741-7015-9-120

Cite this article as: Elleri et al:: Closed-loop insulin delivery for treatment of type 1 diabetes. BMC Medicine 2011 9:120.

\section{Submit your next manuscript to BioMed Central and take full advantage of:}

- Convenient online submission

- Thorough peer review

- No space constraints or color figure charges

- Immediate publication on acceptance

- Inclusion in PubMed, CAS, Scopus and Google Scholar

- Research which is freely available for redistribution

Submit your manuscript at www.biomedcentral.com/submit
C Biomed Central 